\title{
EDITORIAL
}

\section{Ripped from the headlines: how can we harness communications to control TB?}

\author{
G.B. Migliori*, D.M. Cirillo*, A. Spanevello", L.R. Codecasa ${ }^{+}$and Stop TB Italia Group
}

ven 125 yrs after Robert Koch discovered the tuberculosis (TB) bacillus and 63 yrs since the discovery of streptomycin, the first anti-TB drug, TB, the "white plague", still causes $\sim 9$ million incidents of illness and claims $>1.6$ million lives annually. Yet, little attention has been paid to TB by decision-makers, the media or the general public, contributing to a lack of political will and public action to solve this global health emergency. With the recent rekindling of media and popular interest in the emerging threat of extensively drug-resistant TB (XDR-TB), the health community has a critical opportunity to leverage more coordinated and purposeful communications as an important weapon in the fight against TB. Data gathered through the study described below are a starting point for developing a communications strategy and key messages to strengthen Europe's response to the TB epidemic.

\section{FROM SCIENCE TO SENSATIONALISM: WHAT IS TB NEWS?}

TB traditionally receives little media attention; coverage is often limited to large exposures (e.g. cases in schools and workplaces) and dramatic events, such as the high-mortality XDR-TB outbreak among HIV-positive individuals in South Africa [1]. At the start of 2007, Le Iene (the Ienas [2]; a popular evening television broadcast with a high market share in Italy) reviewed coverage of various health issues and "discovered" that the media had in the past given priority and much more relevance to hot-button issues, such as severe acute respiratory syndrome, avian flu and HIV/AIDS (without mentioning its association with TB), than to TB. The Ienas journalists charged one of the Italian national television channels with having forgotten $\mathrm{TB}$, with the effect of raising discussion on this previously neglected disease.

At around the same time, the European Respiratory Journal published a paper describing the threat of XDR-TB [1]. In March 2007, following the publication of a scientific report on 11 XDR-TB cases in Europe (three diagnosed in Germany and

*WHO Collaborating Centre for TB and Lung Diseases, Fondazione S. Maugeri, Care and Research Institute, Tradate, " Supranational Reference Laboratory, S. Raffaele Scientific Institute, and ${ }^{+}$TB Reference Centre, Villa Marelli Institute, Niguarda Hospital, Milan, and "Fondazione S. Maugeri, Care and Research Institute, Cassano delle Murge, Italy.

STATEMENT OF INTEREST: None declared.

CORRESPONDENCE: G.B. Migliori, WHO Collaborating Centre for TB and Lung Diseases, Fondazione S. Maugeri, Care and Research Institute, via Roncaccio 16, 21049, Tradate, Italy. Fax: 39 0331829402. E-mail: gbmigliori@fsm.it eight in Italy, two of whom were resistant to all drugs), a media storm exploded in both countries $[3,4]$. Over a period of 3 weeks, MigLiori and co-workers [1, 3, 4] responded to journalists' questions, which mostly focused on the public's perceived risk of acquiring $\mathrm{TB}$, for instance by travelling by bus or going to the cinema. By chance, media attention occurred the week preceding World TB Day, contributing to additional reports on areas of TB with greater depth.

Following this, news broke of the American lawyer with XDRTB who flew to Europe for his wedding and honeymoon, potentially exposing trans-Atlantic airline passengers, wedding guests, and countless others to XDR-TB $[5,6]$. In spite of health officials urging him not to travel, and subsequent requests by the USA Centers for Disease Control to present himself to a health facility in Italy for evaluation and treatment before travelling further, he continued his journey. He returned to the USA through Canada, slipping across the border despite an alert that should have prevented him from doing so. His clandestine re-entry into the USA, surrender to a health facility in New York and eventual quarantine (the first federal quarantine ordered in $>40$ yrs in the USA) provided a dramatic backdrop for the larger stories of XDR-TB, and the holes in the USA defence systems to protect against infectious disease outbreaks, movement of individuals across borders, etc.

For the most part, what these TB stories have in common is an element of sensationalism, exaggerated risks and individual peril, which is precisely why they make the news. While recent stories certainly have contributed to discussion about TB outside traditional public-health circles, we may wonder what effect they are having on the public and whether they are enough to change the course of TB control locally or globally. In answer to these questions, the results of a recent study are presented, which looked at the knowledge and attitudes towards TB in a general population sample in a high-income, low-TB incidence country within Europe. The aim of the study was to discuss to what extent the surprising results are relevant to European chest physicians and scientific societies (e.g. the European Respiratory Society (ERS)). Although the results reported below are from a single country, we think that they can be of general interest in Europe. To our knowledge, this is the first such study performed in recent years in a highincome, low-TB incidence country.

WHAT DOES THE PUBLIC THINK AND KNOW ABOUT TB? Stop TB Italia Onlus commissioned a survey to evaluate what the public knows and thinks about TB. A population-based cross-sectional study was performed in Italy by DOXA, a major 
Institute of Research Statistics and Analysis of Public Opinion, during February and March 2007. Trained interviewers used a standard questionnaire to interview a cohort of 1,500 adults by telephone, using the computer-assisted telephone interview system. The study households were randomly chosen from a file containing information about households with fixed home telephone numbers and their distribution in different municipalities in the country. A household member was identified for interviewing according to several quotas, including sex per age and per geographical area (quota correlated), education and employment status. Specialists in social sciences and Stop TB Italia Executive Committee members jointly developed the interview questionnaire. It contained true/false, multiple choice (in which responders could choose one or more options) and open-ended questions to gauge knowledge and beliefs about TB.

According to the results of our study, the short answer to the question of what the general public knows and thinks about TB is as follows: 1) many people have heard of TB but know nothing or very little about it; 2) amongst those who have some knowledge, there are still a number of misconceptions; and 3) most people in high-income, low-burden settings see TB as having little relevance to their lives.

Of the 1,500 individuals interviewed, 129 (8.6\%) had never heard of TB, and they were asked no further questions. Of the $1,371(91.4 \%)$ remaining individuals who had heard of TB, 645 ( $43 \%$ of the total cohort) remembered details about it. The demographical and social characteristics of the remaining 726 $(48.4 \%)$ individuals who had heard about TB and stated they knew something about it are presented in table 1. No significant differences were found stratifying by sex, age, education level or geographical location.

\begin{tabular}{ll} 
TABLE 1 & $\begin{array}{l}\text { Demographical and social characteristics of } 726 \\
\text { individuals certain of having the correct knowledge } \\
\text { of tuberculosis (TB) }\end{array}$ \\
Characteristics & $\begin{array}{c}\text { Individuals with } \\
\text { knowledge of TB \% }\end{array}$ \\
\hline Sex & \\
Male & 48.6 \\
Female & 48.2 \\
Age yrs & \\
15-34 & 43.9 \\
35-54 & 50.6 \\
>54 & 49.9 \\
Education & \\
High School/University & 52.0 \\
$\quad$ Years 9-12 and beyond) & \\
Secondary (Years 6-8) & 48.4 \\
Primary (Years 1-5) & 42.5 \\
Geographical region & \\
North-west & 49.4 \\
North-east & 53.8 \\
Central & 47.6 \\
South/islands & 45.1 \\
\hline &
\end{tabular}

The 1,371 individuals who had heard about TB were asked to name one or more characteristic associated with the disease in an open-ended question. Of these, $35 \%$ mentioned that TB is a lung disease, $11.2 \%$ stated that $\mathrm{TB}$ is a serious disease, $7.7 \%$ said that TB is infectious and $4.2 \%$ felt that it can be cured. The majority of the responders did not mention that TB is mainly a pulmonary infectious disease. Only $3.7 \%$ were convinced that TB affects the respiratory tract and that cough $(3.3 \%)$, haemoptysis $(0.9 \%)$ and fever $(0.9 \%)$ are the symptoms of the disease. No significant correlations were identified between spontaneous answers about TB characteristics and the responder's sex, age, education and origin.

Out of the 1,371 individuals who had heard of TB, only 612 $(44.6 \%)$ spontaneously indicated at least one mode of TB transmission. Important defects of knowledge on TB transmission were revealed. Only $19.7 \%$ of the responders correctly identified that TB is transmitted via air. Many were sure that TB is transmitted by direct physical contact $(12.1 \%)$ or via saliva $(8.2 \%)$. Other gaps of knowledge shown in answer to this question included: transmission via blood $(2.7 \%)$, by virus $(2.7 \%)$, from the objects of a TB sufferer $(1.1 \%)$, food $(0.6 \%)$, dirt $(0.5 \%)$ and other factors $(0.9 \%)$. Only when the same responders were asked explicitly about specific descriptors of the disease (i.e. whether it is severe, dangerous, curable, infectious) did the majority interviewed answer correctly. As summarised in table $2,>70 \%$ of the responders answered "yes" or "somewhat" to the questions mentioned above.

Even though our survey has documented that the majority of the population surveyed had at least heard about TB, there were many misconceptions. TB is very often considered to be a disease of the past. More importantly, the younger generation in particular does not associate TB with common risk factors such as HIV/AIDS, immigration from high-burden countries, alcohol abuse, or poverty and homelessness. Within the sample, only 1.9 and $1.1 \%$ of the responders believed that HIV co-infection or another immunocompromised condition, respectively, are risk factors for acquiring TB. Surprisingly, the minority of the responders indicated immigration $(1.9 \%)$ and low income $(1.1 \%)$ to be the risk factors for active TB. Additionally, $\sim 40 \%$ of the responders were not aware of basic facts about TB burden and mortality, either in Italy or globally (table 3).

\section{MOVING FROM EPISODIC REPORTS TO COORDINATED MESSAGES}

The results of this survey point to some serious challenges in efforts to mobilise the political support and additional resources needed for TB control, much of which will be added from high-income, low-burden countries to support the proportionally large inputs from high-burden countries. For the world to reach TB control targets elaborated in the Stop TB Strategy and Millenium Development Goals, we must make up a projected shortfall of US\$31 billion between 2007 and 2015 . Educating the public about the seriousness of the TB crisis and urging individuals and countries to act is clearly in the interest of TB elimination.

The new Stop TB Strategy was launched by the World Health Organization in 2006 [7, 8]. As an integral part of the overall strategy, the Stop TB Partnership recommends advocacy, 


\begin{tabular}{|c|c|c|c|c|c|}
\hline TABLE 2 & $\begin{array}{l}\text { Attitude } \\
\text { (TB) fron } \\
\text { the dise }\end{array}$ & $\begin{array}{l}\text { owards dif } \\
1371 \text { indi } \\
\text { se }\end{array}$ & $\begin{array}{l}\text { erent as } \\
\text { iduals }\end{array}$ & $\begin{array}{l}\text { pects of } \\
\text { tho had }\end{array}$ & $\begin{array}{l}\text { tuberculosis } \\
\text { heard about }\end{array}$ \\
\hline \multirow[t]{2}{*}{ Aspects of TB } & \multicolumn{5}{|c|}{ Attitude \% } \\
\hline & Yes & Somewhat & A little & Not at all & Do not know \\
\hline $\begin{array}{r}\text { Severe (for a } \\
\text { TB patient) }\end{array}$ & 44.0 & 43.3 & 9.2 & 1.4 & 2,1 \\
\hline $\begin{array}{l}\text { Dangerous } \\
\text { (for others) }\end{array}$ & 43.5 & 41.4 & 9.9 & 3.0 & 2.3 \\
\hline Curable & 39.4 & 48.2 & 6.6 & 1.3 & 4.4 \\
\hline Infectious & 31.1 & 39.4 & 13.3 & 7.5 & 8.7 \\
\hline
\end{tabular}

communication and social mobilisation (ACSM) activities to support effective implementation of each of the six components. As summarised in table 4, ACSM is a set of interrelated communication activities, aimed at different target audiences and designed to support TB programme goals locally, nationally and internationally.

Recognising the importance of communications in reaching programmed TB targets, the Stop TB Partnership at the global level created the ACSM Working Group to coordinate efforts at international and country level. In 2006, the Working Group produced guidelines to help develop a coordinated communications strategy for TB entitled "Advocacy, communication and social mobilization to fight TB: a 10-year framework for action". The document describes "a coherent framework designed to use ACSM to help address four key challenges: 1) improving case detection and treatment adherence; 2) combating stigma and discrimination; 3) empowering people affected by TB; and 4) mobilising political commitment and resources for $\mathrm{TB}^{\prime \prime}$ [9].

The challenge for health professionals is to help build upon the opportunities created by the stories people hear about $\mathrm{TB}$, in order to deepen understanding and relevance for policy makers, peers, the media, the public and their patients, leading to actions at all levels to stop TB. In high-income, low-burden countries the fourth challenge is particularly pertinent.

\section{IMPLICATIONS FOR CHEST PHYSICIANS AND SCIENTIFIC SOCIETIES}

For $>20$ yrs, health professionals in high-income, low-incidence countries tried to raise the interest of the media and civil society with modest results. With the recent interest in TB as a result of XDR-TB, the questions are now: "can we capitalise on this interest and direct it in positive ways to achieve the four goals of the ACSM framework listed above?" and "can we truly connect the public to the idea that "TB anywhere is TB everywhere," the theme of the 2007 World TB Day?"

While media stories on XDR-TB have served the purpose of raising TB's profile in the world, it is also important to consider the potentially negative, unintended consequences of such attention. Sensationalistic stories may perpetuate misconceptions, promote fear among the public and add to the stigma of $\mathrm{TB}$, which already plagues people. It is important to supplement the interest-generating function of these stories with simple, compelling and coordinated messages to produce the desired effects: better support for TB control.

The recent TB news events have been effectively managed by health professionals and scientific societies over the last few months. In Germany (Berlin), Italy (Rome), the European Community (Brussels) and in other countries of Europe, World TB Day was celebrated and involved Ministers of Health and Foreign Affairs and important personalities. This allowed the loop described in table 4 to be further expanded. The ERS had a very important role in organising these events. Furthermore, the ERS (a core member of the European Stop TB Partnership) is highly committed to organising the Ministerial Forum on the TB emergency in Europe, which is to be held in Berlin in October 2007. This forum is designed to promote more effective involvement of the European Community in supporting TB control (both financially and technically) in Eastern Europe [1]. These types of activities address the "A" in ACSM. The primary targets for advocacy are politicians and administrators at all levels. As chest physicians and associated professionals, we must address this audience to ensure adequate funding and legal framework to fight against TB. We are progressively learning how to do this from our previous mistakes.

"C" $\mathrm{C}$ " stands for communication. Our capacity to convey correct and effective messages through the media and other channels (creating events at regular time points, according to a

TABLE 3 Answers to questions on stereotypes and awareness of tuberculosis (TB) burden and mortality from 1371 individuals who had heard about the disease

Answers \%

\begin{tabular}{ccc}
\hline True & False & Do not know \\
\hline 62.3 & 28.3 & 9.4 \\
53.4 & 41.9 & 4.7 \\
62.4 & 18.1 & 19.5 \\
61.9 & 21.8 & 16.3 \\
44.7 & 33.3 & 22.0 \\
\hline
\end{tabular}




\section{TABLE 4 Advocacy, communication and social mobilisation in tuberculosis (TB)}

\section{Advocacy}

Activities designed to place TB high on the political and developmental agenda, foster political will, and increase financial and other resources on a sustainable basis

\section{Communication}

Increase knowledge among the general public about TB and TB control services, improve interpersonal communication between patients and programme providers contributing to behavioural change

Social mobilisation

The mobilisation of communities and civil society for action to fight stigma and eliminate TB as a public health threat

The framework works in a $360^{\circ}$ loop, beginning with Advocacy before moving through to Communication, Social mobilisation and back to Advocacy.

communication plan) will increase knowledge about TB among the general public. Of course, to achieve behavioural change (e.g. reduce stigma, generate a proactive approach among patients, families and professionals towards case finding and treatment of TB) is a more difficult issue, with knowledge being only one of its components. Certainly, however, this is an area where chest physicians and scientific societies can play a major role both on an individual patient level and as an integral part of the community.

Scientific societies can also play a critical role in communicating key messages and current standards of TB practice to their members. These concepts are summarised in the International Standards for Tuberculosis Care document, which advocates a patient-centred, sex-sensitive and age-specific approach by both health professionals and health systems $[8,10]$.

SM stands for social mobilisation. Mobilising communities and civil society are other essential actions that occur with sustained efforts over longer time periods to achieve behavioural changes and reach TB targets. Positive results include support for patients to undergo diagnostic and treatment procedures for TB (and HIV/AIDS), resource mobilisation for national and international TB control activities, media attention, and public pressure on administrators and politicians to act.

\section{CONCLUSIONS}

In order to develop a relevant advocacy, communication and social mobilisation strategy for Europe, reliable data on knowledge and attitudes of civil society is necessary in the different countries of Europe. Repeated surveys (similar to that described here) will then mean the impact of advocacy, communication and social mobilisation strategy can be measured. Further steps can be represented by surveys on health professionals' knowledge, attitudes and practice, allowing the impact of promoting guidelines, such as the International Standards for Tuberculosis Care $[8,10]$ and the European Respiratory Society guidelines on tuberculosis management [11] to be measured. The strong coordination existing within the different European Respiratory Society components (Groups, Assemblies, Executive Committee, School, etc.) and its Communication Dept is a testimony to the Society's commitment in supporting advocacy, communication and social mobilisation strategy activities in the fight against tuberculosis and the other respiratory diseases.

\section{ACKNOWLEDGEMENTS}

The authors wish to thank T. Pennas (Edelman, New York, NY, USA) and Siri Wood (PATH, Seattle, WA, USA) for providing table 4 .

The Stop TB Italia Group is comprised of the following Executive and Scientific Committee members. L. Murabito, Stop TB Italia President (Torino, Italy); G. Besozzi (E. Morelli Hospital, Sondalo, Italy); M. Bugiani (TB Dispensary, Torino, Italy); A. Gori (University of Milan, Milan, Italy); and A. Matteelli (University of Brescia, Brescia, Italy). The other members are: O. Toungossova (S. Maugeri Foundation, Cassano delle Murge, Italy); M. D'Arcy Richardson (PATH, Washington DC, USA); G. De Iaco (E. Morelli Hospital, Sondalo, Italy); and R. Centis (S. Maugeri Foundation, Tradate, Italy).

\section{REFERENCES}

1 Migliori GB, Loddenkemper R, Blasi F, Raviglione MC. 125 years after Robert Koch's discovery of the tubercle bacillus: the new XDR-TB threat. Is "science" enough to tackle the epidemic? Eur Respir J 2007; 29: 423-427.

2 Le Iene. www.iene.mediaset.it Date last accessed: June 2007.

3 Migliori GB, Ortmann J, Girardi E. Risk of mortality of extensively drug-resistant tuberculosis (XDR-TB) in Italy and Germany. Emerg Infect Dis 2007; 5: 780-782.

4 Migliori GB, De Iaco G, Besozzi G, Centis R, Cirillo D. First tuberculosis cases in Italy resistant to all tested drugs. Euro Surveill 2007; 12: E070517.1. www.eurosurveillance.org/ ew/2007/070517.asp\#1 Date last accessed: June 2007. Date last updated: June 2007.

5 New York Times. Inquiry into role of Tuberculosis Patient's Father in Law. New York, USA, 2007.

6 Haupt A, Manning A. TB patient test negative, but he is 'culture positive'. USA Today, 2007.

7 Raviglione MC, Uplekar M. WHO's new stop TB strategy. Lancet 2006; 367: 952-955.

8 Migliori GB, Hopewell PC, Blasi F, Spanevello A, Raviglione MC. Improving the TB case-management: the International Standards for Tuberculosis Care. Eur Respir J 2006; 28: 687-690.

9 ACSM Subgroup at Country Level, World Health Organization, Stop TB Partnership. Advocacy, communication and social mobilization to fight TB: a 10-year framework for action. www.stoptb.org/resource_center/ 
assets/documents/TB-ADVOCACY.pdf Date last accessed: June 2007. Date last updated: June 2007.

10 Tuberculosis Coalition for Technical Assistance. International Standards for Tuberculosis Care (ISTC). The Hague, Tuberculosis Coalition for Technical Assistance, 2006.
11 Migliori GB, Raviglione MC, Schaberg T, et al. Tuberculosis management in Europe. Task Force of the European Respiratory Society (ERS), the World Health Organization (WHO) and International Union against Tuberculosis and Lung Disease (IUATLD) Europe Region. Eur Respir J 1999; 14: 978-992. 